\title{
Correction to: Dietary habits of patients with coronary artery disease in a tertiary- care hospital of Bangladesh: a case- controlled study
}

\author{
Taslima Khatun ${ }^{1,2^{*}}$ (D) Dilara Maqbool ${ }^{7}$, Ferdous Ara ${ }^{6}$, Manika Rani Sarker ${ }^{5}$, Kazi Selim Anwar ${ }^{4}$ and Asirul Hoque ${ }^{3}$
}

\section{Correction to: J Health Popul Nutr 40, 3 (2021) https://doi.org/10.1186/s41043-021-00226-1}

Following publication of the original article [1], the authors reported an error in the order of the authors was not the order as it was originally accepted in. The correct order of the authors is indicated hereafter and the changes have been highlighted in bold typeface.

The incorrect order of the author reads:

Taslima Khatun, Asirul Hoque, Kazi Selim Anwar, Manika Rani Sarker, Ferdous Ara and Dilara Maqbool

The correct order of the authors should read:

Taslima Khatun, Dilara Maqbool, Ferdous Ara, Manika Rani Sarker, Kazi Selim Anwar, Asirul Hoque

The changes requested are implemented in this correction and the original article [1] has been corrected.

\section{Author details}

'Department of Public Health, College of Medicine, National Cheng Kung University (NCKU), Taiwan City, Taiwan. ${ }^{2}$ Department of Community Nutrition, Faculty of Public Health, Bangladesh University of Health Sciences (BUHS), 125/1, Darus Salam, Mirpur, Dhaka 1, Bangladesh. ${ }^{3}$ Department of Community Nutrition, Faculty of Public Health, Bangladesh University of Health Sciences (BUHS), 125/1, Darus Salam, Mirpur, Dhaka 1, Bangladesh. ${ }^{4}$ Infectious Diseases Department, International University of Health \& Welfare (IUHW), Narita, Japan. ${ }^{5}$ Department of Community Nutrition, Faculty of Public

The original article can be found online at https://doi.org/10.1186/s41043021-00226-1.

*Correspondence: tasumoni11@yahoo.com

'Department of Public Health, College of Medicine, National Cheng Kung University (NCKU), Taiwan City, Taiwan

${ }^{2}$ Department of Community Nutrition, Faculty of Public Health, Bangladesh University of Health Sciences (BUHS), 125/1, Darus Salam, Mirpur, Dhaka 1, Bangladesh

Full list of author information is available at the end of the article
Health, Bangladesh University of Health Sciences (BUHS), 125/1, Darus Salam, Mirpur, Dhaka 1, Bangladesh. ${ }^{6}$ Department of Food and Nutrition, AkijCollege of Home Economics, Road 9/A (New), House118, Dhanmondi, Dhaka 1209, Bangladesh. 7 Nutrition Officer, LabAid Cardiac Hospital, Dhaka 1205, Bangladesh.

Published online: 13 April 2021

Reference

1. Khatun T, Hoque A, Anwar KS, Sarker MR, Ara F, Maqbool D. Dietary habits of patients with coronary artery disease in a tertiary-care hospital of Bangladesh: a case-controlled study. J Health Popul Nutr. 2021;40:3 https:// doi.org/10.1186/s41043-021-00226-1.

(c) The Author(s). 2021 Open Access This article is licensed under a Creative Commons Attribution 4.0 International License, which permits use, sharing, adaptation, distribution and reproduction in any medium or format, as long as you give appropriate credit to the original author(s) and the source, provide a link to the Creative Commons licence, and indicate if changes were made. The images or other third party material in this article are included in the article's Creative Commons licence, unless indicated otherwise in a credit line to the material. If material is not included in the article's Creative Commons licence and your intended use is not permitted by statutory regulation or exceeds the permitted use, you will need to obtain permission directly from the copyright holder. To view a copy of this licence, visit http://creativecommons.org/licenses/by/4.0/ The Creative Commons Public Domain Dedication waiver (http://creativecommons.org/publicdomain/zero/1.0/) applies to the data made available in this article, unless otherwise stated in a credit line to the data. 